\title{
STRATEGIES OF CONFLICT RESOLUTION AND MITIGATION: THE POTENTIAL OF THE SPEECH ACT OF APOLOGIZING IN THE PERSPECTIVE OF INTERCULTURAL PRAGMATICS
}

\author{
Renate Rathmayr \\ Vienna University of Economics and Business, Vienna, Austria
}

\begin{abstract}
The article considers the linguistic and communicative nature of an apology (a request for forgiveness) as a corrective action that is aimed at preventing or mitigating conflict. By analyzing speech situations from Russian and Austrian culture and their illustrations in literary sources, it is established that apology occupies an intermediate position between performative and non-performative utterance. There have been recorded the situations, where even serious damage can be removed by an apology or an apology in combination with compensation. There are three categories of apologies: metacommunicative, conventional and substantive apologies. The latter two are described in the article. The hypothesis of the study is substantiated by the thesis that the apology depends not only on the severity of the damage, but also on the traditions of culture and peculiarities of the communicative situation. This issue is one of the insufficiently studied questions of linguistics. The article allocates the cultural universals of apologetic speech actions and culturally specific features of apology situations in Russian and Austrian cultures. It is shown that in the sphere of politics, even decades after the infliction of serious harm, a sincere apology for an insult or violation of the norms of behavior, uttered by the responsible person or his descendant, can be the basis for improving inter-state relations.

Key words: speech act of apology, conflict, aggression, conflict prevention, conflict mitigation, Russian culture, Austrian culture, comparative pragmatics.

Citation. Rathmayr R. Strategies of Conflict Resolution and Mitigation: The Potential of the Speech Act of Apologizing in the Perspective of Intercultural Pragmatics. Vestnik Volgogradskogo gosudarstvennogo universiteta. Seriya 2. Yazykoznanie [Science Journal of Volgograd State University. Linguistics], 2020, vol. 19, no. 1, pp. 6-17. (in Russian). DOI: https://doi.org/10.15688/jvolsu2.2020.1.1
\end{abstract}

\section{СТРАТЕГИИ СНЯТИЯ ИЛИ СМЯГЧЕНИЯ КОНФЛИКТА: ПОТЕНЦИАЛ РЕЧЕВОГО АКТА ИЗВИНЕНИЯ В АСПЕКТЕ МЕЖКУЛЬТУРНОЙ ПРАГМАТИКИ}

\section{Ренате Ратмайр}

Венский экономический университет, г. Вена, Австрия

Аннотация. В статье рассматривается лингвистическая и коммуникативная специфика извинения (просьбы о прощении) как корректирующего действия, направленного на предотвращение или смягчение конфликта. Анализ речевых ситуаций извинения в русской и австрийской культурах позволил сделать вывод 
о том, что в некоторых ситуациях извинение занимает промежуточное положение между перформативным и неперформативным высказыванием. Отмечены случаи, когда даже тяжелый ущерб можно снять извинением или извинением в сочетании с возмещением ущерба и другими компенсационными мерами. Из трех категорий извинений, выделенных автором ранее (метакоммуникативные, конвенциональные и извинения по существу), в статье охарактеризованы конвенциональные и извинения по существу. В результате анализа коммуникативных ситуаций, проведенного с использованием методов контрастивной, сопоставительной и межкультурной прагматики, подтверждена авторская гипотеза о том, что извинение зависит не только от тяжести нанесенного ущерба, но и от традиций культуры и особенностей коммуникативной ситуации. В статье выделены культурные универсалии извинительных речевых действий и культурно-специфические признаки ситуаций извинения в русской и австрийской культурах. Показано, что в сфере политики даже спустя несколько десятилетий после нанесения тяжелого ущерба искреннее извинение за оскорбление или нарушение норм поведения, произнесенное ответственным лицом или его потомком, может быть основой для улучшения межгосударственных отношений.

Ключевые слова: речевой акт извинения, конфликт, агрессия, предотвращение конфликта, смягчение конфликта, русская культура, австрийская культура, сопоставительная прагматика.

Цитирование. Ратмайр Р. Стратегии снятия или смягчения конфликта: потенциал речевого акта извинения в аспекте межкультурной прагматики // Вестник Волгоградского государственного университета. Серия 2, Языкознание. - 2020. - T. 19, № 1. - C. 6-17. - DOI: https://doi.org/10.15688/jvolsu2.2020.1.1

\section{Введение}

Согласно теории интеракции извинение это корректирующее действие, направленное на то, чтобы, как указывает У. Фреверт, изменить значение, которое могло бы быть приписано некоторому поступку [Frevert, 1991, S. 156]. Извинения произносятся с целью превратить нечто, что можно принять за агрессию, в нечто, чему можно подобрать приемлемое истолкование. Формулы извинения - это корректирующие ритуальные идиомы. Тот, кто извиняется, входит в данное сообщество; он показывает, что признает действующие в нем правила и нормы. Поэтому извинения - это показатель социальной принадлежности [Manes, Wolfson, 1981, p. 129], так и основанием для межкультурного сравнения. Нарушение социальной нормы, не сопровождающееся извинением, означает, что виновник либо находится в сознательной оппозиции к господствующим нормам, либо не относится к данному обществу, является для него чужим. В связи с этим в социологии извинения также рассматриваются с точки зрения принадлежности извиняющегося к определенному коллективу [Tavuchis, 1991, p. 146].

В русском языке самые частотные формулы извинения - это извини/mе, прости/те; в немецком - entschuldige / entschuldigen Sie и verzeih / verzeihen Sie. Сожаление о случившемся - предпосылка успешного извинения. Однако его выражение в русском языке мне (очень) жаль, в отличие от немецкого tut mir leid и английского sorry, не является принятой формулой извинения. Русское жаль выступает только в контексте более развернутого извинения, например: Извини, пожалуйста, мне очень жаль, что так получилось [Rathmayr, 1995, S. 313]. Объектом извинения могут быть как нечаянные мелочи, так и серьезные оскорбления, как действия на личностном, так и на государственном уровне. Извинения за серьезные нарушения нормы формулируются более развернуто. Какие конфликты можно снять извинением, а по поводу каких обязательно требуется возмещение ущерба или даже обращение в суд, зависит не только от тяжести нанесенного ущерба, но и от культуры, в которой ситуация происходит. В данной статье акцент делается на следующем вопросе: при каких условиях и каким образом слова - совсем не пустые - могут изменить ситуацию в реальном мире.

\section{Материал и методы исследования}

В статье анализируются примеры из русской и австрийской культур, иллюстрирующие ситуации конвенциональных извинений и извинений по существу; используются исследовательские методы контрастивной, сопоставительной и межкультурной прагматики [Developing Contrastive Pragmatics..., 2008; Kecskes, 2014; Mulo Farenkia, 2004; Verschueren, 2016; Wierzbicka, 1991]. В лингвистической 
прагматике учитывается, что сказанное (в его лексическом, грамматическом и синтаксическом значении) далеко не всегда соответствует тому, что говорящий имеет в виду, хочет сказать. Нужны знания о языковом и ситуативном контексте и знания о правилах использования языка, таких как нормы употребления прямых или косвенных высказываний в определенных ситуациях, максимы или постулаты коммуникации [Grice, 1980]. Кроме того, необходимы знания, например, о том, сколько информации уместно приводить, в каких ситуациях это нужно делать и какие именно стратегии вежливости надо использовать и т. п. Если такие прагматические правила более или менее универсальны, то их реализация в разных коммуникативных ситуациях имеют специфический отпечаток определенной культуры, определенного стиля общения. В.И. Карасик, изучая речевую реакцию на извинение (просьбу о прощении), указывает на то, что «общие и специфические характеристики прощения как ценностно маркированного действия в разных культурах еще недостаточно освещены в лингвистической литературе» [Карасик, 2018, с. 77].

В контексте рассматриваемой проблематики интерес представляет контрастивное исследование речи судей, проведенное Т.В. Дубровской [Дубровская, 2014] на эмпирической базе русских, английских и австралийских судебных заседаний. В фокусе ее интересов находится вербальная активность судей, выражение оценок и эмоций, а также вежливость. Различия объясняются как историей и развитием жанра судебной речи в той или иной культуре, так и особенностями стиля речи. Значимы, например, нечеткость границ между личной и профессиональной сферами в русской культуре и, наоборот, противоположное четкое разграничение этих сфер в англосаксонских культурах.

Как это принято в лингвистической прагматике, анализ охватывает не только собственно лингвистические параметры высказывания (лексику, грамматику, синтаксис и стиль) [Норман, 2018], но и экстралингвистические параметры (коммуникативные цели, статус интерактантов, непосредственный и более широкий социальный и исторический контекст), что позволяет сделать выводы об особенностях мышления в тех или иных культурах [Дубровская, 2014, с. 76].

Примеры речевых актов извинения для настоящей статьи были взяты из лингвистической и художественной литературы, публицистики, а также из материалов проведенного мною анкетирования носителей русского языка и интервью с ними [Ратмайр, 2003]. Анкетирование носителей немецкого языка специально не проводилось, но учитывались сведения из лингвистической литературы о функционировании немецкого языка [Cross-Cultural Pragmatics..., 1989; House, Vollmer, 1988; Rehbein, 1972; Vollmer, Olshtain, 1989].

Прагматическое исследование извинений в русском языке в сопоставлении с извинениями в немецком языке [Ратмайр, 2003] показало, что в русской культуре извинения являются в меньшей степени ритуализированными и, как правило, употребляются лишь в таких случаях, когда говорящий испытывает хотя бы минимальное чувство вины. Так, за опоздание на работу из-за болезни ребенка русские скорее не извиняются, они только указывают причину. А в австрийской культуре в такой ситуации обычно произносят формулу извинения. Более того, можно извиниться даже за плохую погоду перед гостями, несмотря на то, что и австрийцы не чувствуют ответственности за погоду и, как и другие, не могут влиять на нее, но в гостеприимство как бы входит и хорошая погода для гостей.

Кроме культурного фактора, естественно, играет роль и индивидуальный фактор, что, например, отражено в рассказе А. Чехова «Смерть чиновника», где показан человек, который умер оттого, что ему не удалось извиниться как следует.

Однако, безусловно, имеются тенденции, характерные для определенной культуры. Все более широкое использование английского языка в качестве lingua franca приводит к распространению английского sorry даже в таких ситуациях, где извините не употреблялось бы.

В исследовании 2003 г. [Ратмайр, 2003] были рассмотрены три категории извинений: метакоммуникативные, конвенциональные и извинения по существу. В рамках настоящей статьи метакоммуникативные извинения мы не приводим, но заимствуем некоторые результаты анализа конвенциональных извине- 
ний и извинений по существу в связи с их потенциалом снятия или смягчения конфликтов.

\section{Результаты и обсуждение}

\section{Конвенциональные извинения}

Конвенциональные извинения произносятся в связи с незначительными нарушениями этикета. Они могут состоять из одной минимальной формулы извинения: извини/те, прости/те, виноват и т. д., но в их состав могут быть включены и расширения. Идеальная ответная реплика, следующая за таким извинением, - это принятие извинения или минимизация ущерба (ну конечно, ничего, не за что, нет проблем). Расширение в составе конвенционального извинения является факультативным. Оно типично для случаев, когда причинен материальный ущерб, который можно исправить, и в такой ситуации действительно нужно восстановить порядок: Извини, ради Бога, я сейчас вытру. В основе конвенциональных извинений нет сильных эмоций, и эти извинения не связаны с самоуничижением говорящего. Они служат для сохранения социальной гармонии в определенном обществе и, вопреки сложившемуся впечатлению, характеризуют говорящего как адаптированного члена социума, соблюдающего его правила. Конвенциональность требует от адресата стереотипной реакции, то есть согласия принять извинение или минимизации ущерба. Молчание обычно расценивается как согласие, хотя вербальная реакция является более вежливой. Различия между вариантами эксплицитных формулировок извинения нейтрализуются и обусловливаются индивидуальными, возрастными или социальными факторами, но не имеют семантической основы. С помощью этих извинений говорящий подтверждает соблюдение норм в смысле «я знаю, что принято». Таким образом, эту категорию извинений можно считать извинениями за нарушения социальных норм и этикета, другими словами, извинениями за «плохое поведение» [Ратмайр, 2003, с. 158].

Извинения за незначительные нарушения этикета связаны с вежливостью в данной культуре. Принято придерживать дверь, поэтому говорят извините, когда этого не де- лают. И в Австрии, и в России принято не толкаться, не опаздывать больше чем на 15 минут, приносить подарки, приходя в гости, и т. д. Если по какой-либо причине толкаются, опаздывают больше чем на 15 минут или не приносят подарка, то извиняются. Считается, что допустимое время, на которое можно опаздывать без предупредительного звонка и извинения, в России больше, чем в Австрии. В деловой сфере в обеих странах принята пунктуальность, а в результате небольшого опроса было выяснено, что на встречу по личному приглашению можно опаздывать без извинения или предупреждения в России на 20 минут, в Австрии - на 15 минут [Ратмайр, 2003, c. 162-163].

Конфликты, вызванные такими нарушениями, небольшие, иногда на них даже не обращают внимания. Извинения за более серьезные поступки предполагают большее количество различий в реакциях на конфликт существенно больше. Извинения по существу мы рассмотрим в зависимости от характера участников общения на личностном и общественном уровнях [Goffmann, 1974]. Отдельно будут описаны извинения в контексте внесудебной компенсации, которые заменяют судебное дело.

\section{Извинения за тяжкие оскорбления и действия на личностном уровне}

Чуть более ста лет назад в определенных ситуациях единственной возможностью защитить свою честь после оскорбления была дуэль [Frevert, 1991], а сейчас во многих европейских обществах конфликт, вызванный тяжким оскорблением, можно снять искренним извинением. Для этого, однако, недостаточно простых ритуальных формул типа извините, простите, entschuldigen Sie, verzeihen Sie, а нужны более развернутые формулировки, включающие объяснения и доказывающие искреннее чувство вины и желание снять конфликт. Реакция на извинение в этикетных случаях необязательна, но обычно бывает эксплицирована: не за что, нет проблем, nichts passiert, keine Ursache и т. п. В случае же серьезного оскорбления чести адресата не только формулировка извинения должна быть адекватной, но должна быть выражена и реакция - желательно, конечно, 
одобрение адресатом. Однако одобрение далеко не всегда следует за извинением по существу, особенно если оно сформулировано с оговоркой. Это скорее способствует возобновлению конфликта, чем примирению. В качестве примера приведу описанный судьей в Инсбруке случай, где не было принято извинение: Если я сказал, что $\mathrm{Bbl- \partial урак,} \mathrm{то} \mathrm{я}$ извиняюсь за это [Ратмайр, 2003, с. 39]. Такие оговорки обесценивают извинение, что приводит к подтверждению оскорбления и развитию конфликта.

В тех случаях, когда извинением нельзя обойтись, а следует обратиться в суд, русская и австрийская культуры также различаются. Если, допустим, в Австрии человек на улице дает пощечину чужому ребенку, то нормальным, обычным следствием этого будет (хотя бы в городе) подача заявления в суд на этого человека. В результате обсуждения аналогичной ситуации в России выяснилось, что в суд обращаться не будут: либо вообще не прореагируют, либо скажут, что «ничего». Обсуждение этой ситуации с информантами показало, что в России скорее принято урегулировать такого типа конфликты без посторонней, тем более судебной, помощи, то есть самостоятельно. Одна женщина-информант, ребенка которой не один раз била соседка, сказала, что смотрит на нее осуждающе и ничего не говорит, чтобы избежать дальнейшей грубости, но ни в коем случае в суд не подаст [Ратмайр, 2003, с. 41]. При воспитании детей такие меры, как пощечина, в России считаются более обычными, чем в Австрии, где давать пощечину нельзя даже своему ребенку: по закону учителя с 1974 г. не имеют права бить учеников, в рамках других профессий это запрещено с 1982 г., а с 1989 г. по австрийской конституции действует абсолютный запрет на использование насилия в воспитании.

Запрет на практике, к сожалению, не означает, что насилие над детьми полностью исчезло (об этом свидетельствует, например, публикация «,,G'sunde Watsch'n“ trotz 30 Jahre Gewaltverbot» в газете «Tiroler Tageszeitung» от 8 ноября 2019 г.).

В России несколько другое отношение к воспитательным мерам, связанным с физическим насилием: россияне, очевидно, пред- почитают урегулировать такого типа «мелочи» без административной помощи.

Отметим, что в основе тяжкого оскорбления необязательно лежат злые намерения. Иногда поступок, вызванный лучшими чувствами, в определенных обстоятельствах может оказаться тяжким оскорблением. Такую ситуацию описывает М. Зощенко в рассказе «Мелкий случай из личной жизни». Герой-рассказчик стоит перед входом в кинотеатр и ждет даму. В это время он замечает старушку, которая, не прося вслух милостыню, стоит «скромно и даже как-то стыдливо». Объятый гуманными чувствами, герой дает женщине рубль (что было тогда немалой суммой!), но, вместо того чтобы выразить благодарность, старушка приходит в настоящую ярость, ведь она всего лишь ждет здесь свою дочь:

- Странно, - говорит, - я, кажется, не прошу. Чего вы мне рубль пихаете... Может быть, я дочку жду - собираюсь с ней в кино пойти. Очень, - говорит,- обидно подобные факты видеть.

Я говорю:

- Извиняюсь... Как же так... Я прямо сам не понимаю... Пардон, говорю. Прямо спутался. Не поймешь, кому чего надо. И кто зачем стоит. Шутка ли, столько народу. Пойди, разбирайся.

Но старуха поднимает голос до полного визга.

- Это что ж, - говорит, - в кино не пойти оскорбляют личность! Как, говорит, у вас руки не отсохнут производить такие жесты. Да я лучше подожду дочку и в другое кино пойду, чем я буду с вами сидеть рядом и дышать зараженным воздухом.

Я хватаю ее за руку, извиняюсь и прошу прощения (URL: http://www.zoschenko.info/cat/224/ 76.html (дата обращения: 08.07.2019)).

Этот пример недвусмысленно иллюстрирует идею, которую однажды приходится осознать каждому: даже хорошие намерения могут привести к серьезному оскорблению, которое невозможно загладить ничем, кроме искреннего извинения. Однако, как это часто бывает в рассказах М. Зощенко, ситуация изменяется парадоксальным образом: через некоторое время старушка сама извиняется перед героем-рассказчиком и просит его все-таки дать ей рубль, потому что иначе она не сможет позволить себе такое место в кинотеатре, с которого она хоть что-нибудь увидит, ведь у нее такое плохое зрение (подробно анализ этого рассказа дан в: [Ратмайр, 2003, с. 189-190]). 
У (австро-)венгерского автора Ференца Мольнара находим написанную в начале XX в. пьесу «Лилиом», герой которой платит своей жизнью за неспособность извиниться:

Просить прощения... это нет. ...Я не могу... я не извиняюсь (Molnar F. Liliom // Burgtheater Programm Nr. 113. Wien, 1993. S. 66).

Определение того, что считается оскорблением, чего нельзя говорить, является достаточно сложной задачей, хотя в законах такие определения есть. Существует противоречие между правом на свободу убеждений и свободное их выражение и пределом, за которым находятся hate speech, Shitstorm и Cybermobbing. В Венском экономическом университете 29 мая 2019 г. под руководством юриста, специалиста по гражданскому праву профессора Мартиа Шпитцера проводилась публичная дискуссия на тему «WUmatters. WUtalks - Darf man das sagen?» (Что можно сказать?). Сложная проблематика обсуждалась на примере дела присутствующей на трибуне женщины, которая получила весьма неприличные посты с аккаунта владельца пивного ресторана. Она в Сети отреагировала на оскорбления, на что владелец аккаунта обвинил ее в клевете. Судом первой инстанции женщина была признана виновной в клевете, и только вторая инстанция отменила обвинение. Процесс продолжится в сентябре 2019 года.

Удивительное судебное решение было принято в случае с фанатом австрийской футбольной команды «Рапид»: он в апреле 2017 г. на стадионе «Аллианц» размахивал транспарантом с надписью «А.С.A.В.» (All Cops are Bastards. - Bce полицейские - идиоты / ублюдки). Судом первой инстанции он был признан виновным, а сейчас Конституционный суд принял решение, что фанат использовал свое право на свободу убеждений и свободное их выражение. Размахивание транспарантом не является оскорблением конкретного полицейского, и поэтому с этим действием нужно смириться (Der Standard. 05.07.2019. S. 23). Штраф был отменен, и Вена как федеральная земля должна вернуть фанату «Рапида» 2 900,00 евро за судебные издержки (статья «Keine Strafe für "All Cops Are Bastards" in vollem Stadion» в газете «Kurier» от 4 июля 2019 г. и статья «Rapid-Fans gegen Wiener
Polizei: Fortsetzung vor Gericht» B «Der Standard» от 12 июля 2019 г.).

\section{Извинения за тяжкие оскорбления и причинение тянкого вреда на общественном уровне}

Практика показывает, что в некоторых случаях за очень тяжкие проступки и нарушения норм поведения можно всего лишь извиняться. Примером такой ситуации на межгосударственном уровне является извинение австрийского федерального канцлера Франца Враницкого за преступления Холокоста во время Второй мировой войны. Эксплицитное признание вины и извинение состоялись спустя довольно длительное время и были очень тщательно продуманы: федеральный канцлер Ф. Враницкий в июле 1991 г. сказал по этому поводу в Национальном совете, то есть в австрийском парламенте:

Многие граждане Австрии были причастны к угнетению и преследованию, организованным Третьим рейхом, а некоторые были их видными участниками, и сегодня мы не можем не считаться с участием в ответственности за деяния наших сограждан. <..> Мы признаем себя причастными ко всем важным датам нашей истории и всем поступкам, совершенным нашим народом, - как хорошим, так и плохим; и подобно тому, как мы можем гордиться хорошими поступками, за плохие мы должны принести свои извинения - перед теми, кто выжил, и перед потомками мертвых (заявление федеральной пресс-службы в «Wiener Journal» (1991. № 9); перевод мой. - P. Р.).

Такие же весомые извинения были и в истории других государств. В договоре о дружбе между Россией и Чехией осуждается ввод войск Советского Союза и других стран Варшавского договора в Прагу в 1968 году. Подпись Б. Ельцина под этим документом, безусловно, не является официальным извинением, которого открыто требовала радикально-демократическая группа депутатов в России и некоторые официальные лица в Чехии, но практически ее можно приравнять к извинению. То же можно сказать и о возложении венка к памятнику 15 тысячам жертв кровавой расправы в Катыни и выражении Б. Ельциным соболезнований родным и близким погибших (Независимая газета. 27.08.1993; 
Известия. 26.08.1993; Известия. 27.08.1993). Во всех этих случаях извинения принесены спустя много лет после совершения несправедливых действий (подробнее см.: [Ратмайр, 2003, с. 206-211]).

За другие действия во время Второй мировой войны - бомбардировки Хиросимы и Нагасаки - извинения не прозвучало и 71 год спустя, во время первого визита американского президента в Японию. РИА «Новости» 27 мая 2016 г. в статье «Визит Обамы в Хиросиму: исторический момент и никаких извинений» сообщает о визите Б. Обамы и об ожиданиях и требованиях извинения со стороны японских демонстрантов. Профессор Бостонского университета Томас Бергер отмечает важное значение визита Обамы для укрепления связей США и Японии. В частности, он считает, что поездка в Хиросиму может быть своеобразным ответом тем консервативным силам в Японии, которые выступают за пересмотр традиционной критической точки зрения на «имперское прошлое» страны (статья «Политологи оценили риски, которые ждут Обаму во время визита в Хиросиму» в РИА «Новости» от 27 мая 2016 г.). Профессор сказал о том, что, хотя президент Обама не принесет извинений, само посещение Хиросимы и выражение сочувствия пострадавшим укрепит позиции тех японцев, которые хотят более позитивного, нацеленного на будущее подхода к тому, как Япония воспринимает сложную проблему своего имперского прошлого. Решение о визите еще не было принято, а официальные лица уже начали высказываться о том, стоит ли ждать извинений за причиненные японским городам несчастья. США недвусмысленно дали понять, что извинений не будет. Эта позиция осталась неизменной: в интервью японскому телеканалу «NHK» Б. Обама заявил, что не намерен просить прощения. Американский президент сказал:

Моя цель - не просто обратиться к прошлому, а подтвердить, что в войнах со всех сторон умирают невинные люди, и мы должны сделать все возможное, чтобы постараться обеспечить мир и диалог во всем мире. Что мы должны продолжать бороться за мир без ядерного оружия. Это то, над чем я работал с того момента, как я впервые вступил в должность (РИА «Новости». 27.05.2016; Die Presse. 28.05.2016).
Иногда извинение или выражение раскаяния может привести к смягчению наказания. Например, в России обвиняемый в покушении на царя брат Ленина Александр отказался покаяться и был казнен, хотя его мать вымолила помилование для сына с условием его раскаяния. Поскольку тот отказался раскаяться, смертная казнь состоялась (Васильева Л. Н. Кремлевские жены : Факты, воспоминания, документы, слухи, легенды и взгляд автора. М. : Вагриус, 1993. С. 34).

В более близкой к нам истории прозвучали извинения Б. Ельцина за гибель трех молодых людей во время путча в августе 1991 г.: на похоронах жертв августовского путча Б. Ельцин открыто извинился перед их родителями:

Простите меня, что не смог защитить, уберечь ваших сыновей (Известия. 24.08.1993. С. 1).

Это первое в России извинение политика в присутствии общественности в высшей степени примечательно: Б. Ельцин не может привести в свое оправдание никаких аргументов, и как президент Российской Федерации он несет ответственность за то, что произошло в стране, именно поэтому он употребляет слово простите (и в этом случае его нельзя заменить словом извините, ср.: *Извините меня, что не смог защитить, уберечь ваших сыновей). Поскольку во время путча Б. Ельцин боролся на той же стороне, что и жертвы, и сам путч был, собственно, направлен против ГКЧП, он лишь косвенным образом повинен в смерти этих молодых людей, и поэтому его извинение было благородным жестом (подробнее об этом см.: [Ратмайр, 2003, c. 203-204]).

31 января 2018 г. В.В. Путин попросил прощения у российских спортсменов за то, что руководство Российской Федерации не смогло защитить их от последствий допингового скандала в 2014 г. в Сочи, приведшего к исключению многих спортсменов из числа участников Олимпийских игр в Пхенчхане. Как известно, в Олимпийских играх в Южной Корее из России могли участвовать только 169 спортсменов под нейтральным олимпийским флагом. На встрече со спортсменами В.В. Путин попросил у них прощения за ситуацию с Олимпиадой-2018: 
Простите нас за то, что мы не смогли вас от этого [нападок] оградить (URL: http://mosday.ru/ news/item.php?1328482\&view=full (дата обращения: 01.07.2019)).

Заметим, что для смягчения серьезного общественного конфликта существует возможность извинения за нанесенный ущерб не самого виновного, а его начальника, то есть лица, ответственного за виновника. Это произошло, например, в случае извинения архиепископа Австрии кардинала Кристофа Шенборна за действия предыдущего венского архиепископа Ганса Германа Гроера, который объяснил свои поступки (сексуальное насилие, в том числе и по отношению к детям) слишком мягко и двусмысленно. К. Шенборн в рамках публичного выступления попросил прощения за все, чем его предшественник и другие церковные деятели нанесли ущерб тем людям, которые им доверяли. Дополнительно он обещал помощь всем потерпевшим и подтвердил, что Г.Г. Гроер покинет Австрию (статья «Chronologie der Causa Groer» в газете «Der Standard» от 17 апреля 1989 г.). В мае 2010 г. К. Шенборн сказал австрийскому информационному агентству католической прессы «Kathpress», что дни сокрытия и утаивания правды закончены. Долгое время церковный принцип прощения ложно интерпретировался и защищал виновных, а не жертв, хваля Папу Римского Бенедикта XVI за его стремление разоблачить священников, совершавших сексуальное насилие. Ганс Герман Гроер покинул кафедру в 1995 г. и сложил с себя все духовные обязанности и привилегии как архиепископ и кардинал 14 апреля 1998 г. (URL: http://ru.knowledgr.com/00887520/КристофШенборн (дата обращения: 02.07.2019)).

Нередки случаи общественного призыва к извинениям. Например, венский городской советник по транспорту Мария Вассилакоу начала кампанию под названием «Tschuldigens nie verkehrt» («Извиниться никогда не мешает»), сформулированным на венском диалекте (Der Standard. 01.06.2012. S. 10). $\mathrm{B}$ ходе кампании она призывала к большей приветливости и взаимной предупредительности всех участников уличного движения, включая бесцеремонных велосипедистов. Так она отреагировала на растущее количество конфликтов на улицах, которое стало темой обсуж- дения в Вене. Целью кампании было повысить ответственность всех участников уличного движения и обеспечить их безопасность, независимо от того, пешеход это, велосипедист или автомобилист. Был показан видеоролик с диалогом между байкером, который едва успел остановиться перед пешеходным переходом, и находящейся на «зебре» женщиной: «Tschuldigen (извините)», - говорит байкер. «Passt schon (ладно)», - отвечает женщина (Tschuldigen - сокращенная диалектная форма от entschuldigen Sie). Применялись и плакаты, и флайеры, и стикеры, на «Ютубе» показывали видеофильм. Осенью кампания продолжилась в школах. По цели она напоминает призыв «Уважаемые пассажиры, будьте взаимно вежливы, уступайте места инвалидам, пожилым людям, пассажирам с детьми», который часто можно услышать в московском метро (правда, речь не об извинениях, а шире о вежливом поведении в транспорте).

\section{Извинения в контексте внесудебной компенсации}

В 1990-е гг. в Австрии была законодательно закреплена возможность внесудебной компенсации в определенных - не слишком серьезных - случаях, даже когда дело уже было подано в суд. Кроме материальной компенсации частью этого способа урегулирования конфликта является извинение.

Так называемый «Аußergerichtlicher Tatausgleich (= Diversion)» - внесудебная компенсация - заключается в том, что уголовное дело заканчивается вне суда, без заведения судебного дела и штрафа, а, например, условным сроком, общественными работами, уплатой возмещения материального или морального ущерба и извинением. Внесудебная компенсация возможна только при определенных условиях: нетяжкое преступление, нетяжкая вина преступника, если обвиняемый признает свою вину, если он сожалеет о случившемся, если у него нет прежней судимости такого типа (URL: https://www.kija.at/a-z/gesetzesuebertretungen/ 265-strafe-wiedergutmachung (дата обращения: 02.07.2019)).

В статье «Извинения достаточно - штраф не нужен» («Entschuldigung reicht als Strafe») coобщается о 16-летнем подростке из австрий- 
ской земли Форарльберг (Vorarlberg), который сломал два ребра 58-летнему гражданину Хохенемса (Hohenems) и вместо штрафа обошелся внесудебной компенсацией. Он извинился, и участники конфликта разошлись, обменявшись рукопожатиями и ограничившись пожеланием пострадавшего в адрес виновника: «Держись» (URL: https://www.vol.at/ vorarlberg-entschuldigung-reicht-als-strafe/ 5960312 (дата обращения: 02.07.2019)).

Приведем еще один пример. В статье «Smiley statt Strafzettel, Parksheriff zeigt Gnade» («Смайл вместо штрафной квитанции. Контролер проявил милость») сообщается, что 20 декабря 2017 г., то есть за несколько дней до Рождества, австрийский студент, который в свободное время работал таксистом, вместо квитанции за оплату стоянки оставил на лобовом стекле автомобиля извинение:

Hatte leider keine Zeit 2h Parkticketzukaufen. Mussteins Training, Student. Bitte um Verständnis!-) (К сожалению, у меня не было времени купить талон на 2 часа. Спешил на тренировку, студент. Прошу Вашего понимания!).

Добродушный контролер оставил записку: «Verziehen $\odot$ » (Простил/а) $)$.

Студент прокомментировал: «Sehr sympathisch, das nächste Mal habe ich wieder einen Parkschein!» (Очень приятно, в следующий раз уменя будет опять талон на парковку) (URL: https://www.heute.at/ community/leser/story/Smiley-statt-StrafzettelParksheriff-zeigt-Gnade-59567374 (дата обращения: 02.07.2019)).

В России возможность внесудебного урегулирования конфликта тоже существует. Приведем два примера. На канале «Ютуб» под заголовком «Извинения вместо штрафа» 1 августа 2013 г. была размещена информация о том, что в Кирове кондуктор якобы вытолкнула из автобуса ученика третьего класса, так как он отказался платить за школьный рюкзак. По суду кондуктору автобуса грозил штраф 40000 рублей. Родители мальчика согласились на примирение:

Мы с женой оба сказали, что если будут принесены извинения, если она признает вину, то у нас больше претензий нет. Больше комментировать не буду (URL: https://www.youtube.com/watch?v=8dgsgW7WE8 (дата обращения: 02.07.2019)).

2 июля 2019 г. на портале «Лента.ру» сообщалось об извинении губернатора Красно- ярского края Александра Усса, который ранее угрожал жительнице затопленного Канска «тоже качнуть права». Депутат Госдумы Евгений Ревенко заявил, что губернатор Красноярского края Александр Усс должен извиниться за свои грубые слова в адрес местной жительницы. Губернатор действительно извинился перед женщиной за резкие высказывания. Об этом 2 июля сообщило РИА «Новости» со ссылкой на участницу разговора. По словам Натальи, глава региона в ходе телефонного разговора пообещал, что вопрос с дорогой в подтопленной зоне будет решен:

Конкретно по вопросу, который я задала, он мне ответил. Уже сегодня там работы ведутся, оснований ему не верить нет (URL: https://lenta.ru/news/ 2019/07/02/pardon/ (дата обращения: 02.07.2019)).

Таким образом, мы видим, что и в Австрии, и в России искренние слова извинения могут влиять на неязыковую ситуацию, могут уберечь человека, поступившего неправильно, от штрафа, от признания его преступником. Условием успешности таких извинений является искренность, чувство вины у нарушителя и согласие пострадавшего принять извинения. Эти «мягкие» межчеловеческие параметры обладают большей силой, чем ожидается.

\section{Заключение}

Речь нельзя рассматривать наравне с неязыковыми действиями, поскольку она всегда является действием символическим. С помощью слов можно подготовить внеязыковое действие и даже сделать возможным то, что было невозможно раньше. Только в исключительных случаях, например в перформативных речевых актах, язык может непосредственно влиять на внеязыковую действительность. Когда директор говорит $B b l$ уволены, адресат этого высказывания на самом деле остается без работы, а после слов работника ЗАГСа Поздравляю вас и объявляю мужем $u$ женой мужчина и женщина становятся мужем и женой со всеми вытекающими из этого правами и обязанностями.

Речевой акт извинения, то есть просьба о прощении (об извинении), занимает некоторое промежуточное положение: после его произнесения можно считать досадное языковое 
или неязыковое действие (или упущение) неслучившимся, несказанным: Забудем об этом; Я уже забыла. Извинение устранило неудачу, как будто ее и не было. Следовательно, хотя извинение, конечно, не может повернуть реальное время вспять и помешать случиться тому, что уже случилось, успешное извинение влияет на ситуацию и на партнеров коммуникации таким образом, что на внеязыковом уровне они действуют так, как будто ничего отрицательного не произошло.

В данной статье были рассмотрены конвенциональные, или этикетные, извинения, нормальные для вежливого поведения носителей русской и австрийской культур. Далее были представлены случаи извинений по существу, то есть извинений за тяжкие оскорбления и нанесение тяжкого материального или морального ущерба. Проанализированы примеры как из личностной сферы общения, так и из общественной. Показано, что в сфере политики даже спустя несколько десятилетий после нанесения тяжкого оскорбления или нарушения норм поведения искреннее извинение, произнесенное ответственным лицом или его потомком, может быть основой для улучшения межгосударственных отношений.

\section{СПИСОК ЛИТЕРАТУРЫ}

Дубровская Т. В., 2014. Судебный дискурс как культурный феномен: национально-культурные особенности речи судей (на материале русских, английских и австралийских судебных заседаний) // Вопросы языкознания. № 2 . C. $76-88$.

Карасик В. И., 2018. Аксиология прощения в русской и английской лингвокультурах // Лингвокультурные ценности в сопоставительном аспекте : коллектив. моногр. / науч. ред. В. И. Карасик, Н. А. Красавский. Волгоград : ПринТерра-Дизайн. С. 76-94.

Норман Б. Ю., 2018. Прагматический потенциал русской лексики и грамматики. М. : Кабинетный ученый. 464 с.

Ратмайр Р., 2003. Прагматика извинения : Сравнительное исследование на материале русского языка и русской культуры. М. : Яз. слав. культуры. 272 c. (Studiaphilologica. Series minor).

Cross-Cultural Pragmatics: Requests and Apologies, 1989 / ed. by S. Blum-Kulka, J. House, G. Kasper. Norwood, New Jersey: Ablex Publ. Corporation. $300 \mathrm{p}$.
Developing Contrastive Pragmatics. Interlanguage and Cross-Cultural Perspectives, 2008 / ed. by M. Pütz, J. Neff-van Aertselaer. Berlin ; N. Y. : Mouton de Gruyter. $437 \mathrm{p}$.

Frevert U., 1991. Ehrenmänner. Das Duell in der bürgerlichen Gemeinschaft. München : Beck. $376 \mathrm{~S}$.

Goffmann E., 1974. Das Individuum im öffentlichen Austausch. Mikrostudien zur öffentlichen Ordnung. Frankfurt am Main : Suhrkamp Verl. $512 \mathrm{~S}$.

Grice H. P., 1980. Logik und Gesprächsanalyse // Sprechakttheorie / hrsg. von P. Kußmaul. Wiesbaden : Athenaion. S. 109-126.

House J., Kasper G., 1981. Politeness Markers in English and German // Conversational Routine. Explorations in standardized Communication Situations and Prepatterned Speech / ed. by F. Coulmas. N. Y. : Mouton Publishers. P. 157-185.

House J., Vollmer H. J., 1988. Sprechaktperformanz im Deutschen: Zur Realisierung der Sprechhandlungen „Bitten/ Auffordern“ und „Sich entschuldigen“// Linguistische Berichte, Nr. 114. S. 114-133.

Kecskes I., 2014. Intercultural Pragmatics. Oxford : Oxford University Press. 277 p.

Manes J., Wolfson N., 1981. The Compliment Formula // Conversational Routine: Explorations in Standardized Communication Situations and Prepatterned Speech / ed. by F. Coulmas. The Hague, the Netherlands : Mouton Publishers. P. 116-132.

Mulo Farenkia B., 2004. Kontrastive Pragmatik der Komplimente und Komplimenterwiderungen: Kamerunisch - Deutsch. Aachen : Shaker. 144 S.

Rathmayr R., 1995. Sprechakte, Gesprächszüge und kulturspezifische Gebrauchskonventionen. Am Beispiel des Russischen // Slavistische Linguistik 1994 / hrsg. von D. Weiss. München : O. Sagner. S. 311-332. (Münchner Slavistische Beiträge ; Bd. 332)

Rehbein J., 1972. Entschuldigungen und Rechtfertigungen // Linguistische Pragmatik / hrsg. von D. Wunderlich. Frankfurt am Main : Athenaum. S. 288-317.

Tavuchis N., 1991. Mea Culpa. A Sociology of Apology and Reconciliation. Stanford : Stanford University Press. 165 p.

Verschueren J., 2016. Contrastive Pragmatics // Handbook of Pragmatics 20 / ed. by J.-O. Östman, J. Verschueren. Amsterdam : John Benjamins. P. $1-34$.

Vollmer H. J., Olshtain E., 1989. The Language of Apologies in German // Cross-Cultural Pragmatics: Requests and Apologies / ed. by S. Blum-Kulka, J. House, G. Kasper. Norwood, 
New Jersy : Ablex Publishing Corporation. P. $197-218$

Wierzbicka A., 1991. Cross-Cultural Pragmatics. The Semantics of Human Interaction. Berlin ; N. Y. : Mouton de Gruyter. 502 p.

\section{REFERENCES}

Dubrovskaya T.V., 2014. Sudebnyy diskurs kak kulturnyy fenomen: natsionalno-kulturnye osobennosti rechi sudey (na materiale russkikh, angliyskikh i avstraliyskikh sudebnykh zasedaniy) [The Discourse of Court as a Cultural Phenomenon: National Cultural Features in the Speech of Judges (Case Studies of Court Sessions in Russia, England, and Australia)]. Voprosy yazykoznaniya [Topics in the Study of Language], no. 2, pp. 76-88.

Karasik V.I., 2018. Aksiologiya proshcheniya v russkoy $\mathrm{i}$ angliyskoy lingvokulturakh [Axiology of Forgiveness in Russian and English Linguocultures]. Karasik V.I., KrasavskiyN.A., eds. Lingvokulturnye tsennosti $v$ sopostavitelnom aspekte: kollektiv. monogr. [Linguistic and Cultural Values in a Comparative Aspect. Collective Monograph]. Volgograd, PrinTerra-Dizayn Publ., pp. 76-94.

Norman B.Yu., 2018. Pragmaticheskiy potentsial russkoy leksiki i grammatiki [Pragmatic Potential of Russian Vocabulary and Grammar]. Moscow, Kabinetnyy uchenyy Publ. 464 p.

Ratmayr R., 2003. Pragmatika izvineniya: Sravnitelnoe issledovanie na materiale russkogo yazyka $i$ russkoy kultury [Pragmatics of Apologizing. Comparative Research Based on the Russian Language and Russian Culture]. Moscow, Yazyki slavyanskikh kultur Publ. 272 p. (Studiaphilologica. Series minor).

Blum-Kulka S., House J., Kasper G., eds., 1989. CrossCultural Pragmatics: Requests and Apologies. Norwood, New Yersey, Ablex Publ. Corporation. $300 \mathrm{p}$.

Pütz M., Neff-van Aertselaer J., eds., 2008. Developing Contrastive Pragmatics. Interlanguage and Cross-Cultural Perspectives. Berlin, New York, Mouton de Gruyter. 437 p.

Frevert U., 1991. Ehrenmänner. Das Duell in der bürgerlichen Gemeinschaft. München, Beck. 376 S.

Goffmann E., 1974. Das Individuum im öffentlichen Austausch. Mikrostudien zur öffentlichen
Ordnung. Frankfurt am Main, Suhrkamp Verl. $512 \mathrm{~S}$.

Grice H.P., 1980. Logik und Gesprächsanalyse. Kußmaul P., Hrsg. Sprechakttheorie. Wiesbaden, Athenaion, S. 109-126.

House J., Kasper G., 1981. Politeness Markers in English and German. Coulmas F., ed. Conversational Routine. Explorations in Standardized Communication Situations and Prepatterned Speech. New York, Mouton Publishers, pp. 157-185.

House J., Vollmer H.J., 1988. Sprechaktperformanz im Deutschen: Zur Realisierung der Sprechhandlungen „Bitten/ Auffordern“ und „Sich entschuldigen“. Linguistische Berichte, Nr. 114, S. 114-133.

Kecskes I., 2014. Intercultural Pragmatics. Oxford, Oxford University Press. 277 p.

Manes J., Wolfson N., 1981. The Compliment Formula. Coulmas F., ed. Conversational Routine: Explorations in Standardized Communication Situations and Prepatterned Speech. The Hague, the Netherlands, Mouton Publishers, pp. 116-132.

Mulo Farenkia B., 2004. Kontrastive Pragmatik der Komplimente und Komplimenterwiderungen: Kamerunisch - Deutsch. Aachen, Shaker. 144 S.

Rathmayr R., 1995. Sprechakte, Gesprächszüge und kulturspezifische Gebrauchskonventionen. Am Beispiel des Russischen. Weiss D., Hrsg. Slavistische Linguistik 1994. München, O. Sagner, S. 311-332. (Münchner Slavistische Beiträge, Bd. 332).

Rehbein J., 1972. Entschuldigungen und Rechtfertigungen. Wunderlich D., Hrsg. Linguistische Pragmatik. Frankfurt am Main, Athenaum, S. 288-317.

Tavuchis N., 1991. Mea Culpa. A Sociology of Apology and Reconciliation. Stanford, Stanford University Press. $165 \mathrm{p}$.

Verschueren J., 2016. Contrastive Pragmatics. Östman J.O., Verschueren J., eds. Handbook of Pragmatics 20. Amsterdam, John Benjamins, pp. 1-34.

Vollmer H.J., Olshtain E., 1989. The Language of Apologies in German. Blum-Kulka S., House J., Kasper G., eds. Cross-Cultural Pragmatics: Requests and Apologies. Norwood, New Jersy, Ablex Publishing Corporation, pp. 197-218.

Wierzbicka A., 1991. Cross-Cultural Pragmatics. The Semantics of Human Interaction. Berlin, New York, Mouton de Gruyter 502 p. 


\section{Information About the Author}

Renate Rathmayr, Doctor of Sciences (Philology), Professor, Department of Foreign Language Business Communication, Institute of Slavic Languages, Vienna University of Economics and Business, Welthandelsplatz, 1, D2.3.202,A-1020 Vienna,Austria, renate.rathmayr@wu.ac.at, https://orcid.org/0000-0003-3038-2276

\section{Информация об авторе}

Ренате Ратмайр, доктор филологических наук, профессор кафедры делового общения на иностранных языках, Институт славянских языков, Венский экономический университет, Welthandelsplatz, 1, D2.3.202,А-1020 г. Вена, Австрия, renate.rathmayr@wu.ac.at, https://orcid.org/0000-0003-3038-2276 